\title{
Effect of sintering temperature on adhesion of spray-on piezoelectric transducers
}

\author{
Kyle M. Sinding ${ }^{1}$, Alison Orr ${ }^{2}$, Luke Breon ${ }^{3}$, and Bernhard R. Tittmann ${ }^{1}$ \\ ${ }^{1}$ Pennsylvania State University, University Park, Pennsylvania, USA \\ ${ }^{2}$ Misonix Inc. in Farmingdale, New York, USA \\ ${ }^{3}$ Electric Power Research Institute, Charlotte, North Carolina, USA \\ Correspondence to: Bernhard R. Tittmann (brt4@psu.edu)
}

Received: 30 July 2015 - Revised: 8 January 2016 - Accepted: 9 March 2016 - Published: 1 April 2016

\begin{abstract}
Conventionally sol-gel spray-on transducers require a high-temperature $\left(>700{ }^{\circ} \mathrm{C}\right)$ sintering process; however, this process can affect the microstructure of the substrate material. For mechanical elbows and valves utilized for fluid transport in the energy sector, the components are designed to have a specific microstructure, and deviations from these specifications can create weak points in the system. For this reason it is important to investigate how the temperature of the deposition process affects the substrate. This paper investigates the effect of high-temperature and low-temperature $\left(<150^{\circ} \mathrm{C}\right)$ processing conditions on the surface composition of the substrate. Furthermore, the resultant transducers from high- and low-temperature fabrication processes are compared to determine if a low-temperature processing method is feasible. For these studies a sol-gel spray-on process is employed to deposit piezoelectric ceramics onto a stainless-steel $316 \mathrm{~L}$ substrate. Energy-dispersive X-ray spectroscopy is utilized to determine the composition of the substrate surface before and after transducer deposition. Results indicate that the high-temperature processing conditions may alter the surface composition of the metal due to a diffusion of the metal into the ceramic, which results in a metal surface that is bonded to the ceramic. Furthermore, it is shown that low-temperature processing of spray-on transducers is a viable method for transducer fabrication where the resultant transducers meet the industry minimum requirement of $30 \mathrm{~dB}$ signalto-noise ratio. In parallel simulation calculations, finite-element method (FEM) studies were performed to model the adhesive strength of the low-temperature processed transducer to the substrate surface. Comparisons between the simulations and experiments suggest that the bond strength is much greater than the commercial gel bonds and closer to hardened epoxy glue bonds. These results indicate that spray-on transducers fabricated under lowtemperature processing conditions are a viable solution for leave-in-place monitoring of structures.
\end{abstract}

\section{Introduction}

\subsection{Goals and objectives}

The goal of this work was to do research and development of the fabrication and attachment of leave-in-place ultrasonic spray-on transducers to metallic tubular structures. In particular, the objective was to investigate the effect of the spray-on transducer deposition process on the bond adhesion strength to metal alloy substrates when deposited at relatively low temperatures. A further objective was to compare the bond strength between the spray-on transducer and commercial adhesives such as those used for in-field conventional ul- trasonic non-destructive evaluation (UNDE). The motivation for this investigation was that permanently installed sensors utilizing this work could offer advantages in implementation over periodically applied conventional UNDE for piping systems in energy production facilities, such as secondary systems in nuclear reactors, where elevated temperatures and low-level radiation limit the presence of personnel.

The following steps were taking to achieve this goal:

1. The physical bond between a high weight percent of bismuth titanate (BiTi) material and a metal substrate fabricated at both high and low temperatures was examined in order to show that the signal-to-noise ratio (SNR) is 
independent of the fabrication temperature between 100 and $700^{\circ} \mathrm{C}$.

2. A baseline was set up in order to characterize the sprayon transducer's bond strength. For this a high weight percent of BiTi material (BT200) was obtained and bonded to a metal substrate with a commercial adhesive. This combination was modeled and simulated for various commercial adhesives.

3. Finally, having shown that the fabrication temperature does not play a major role, several transducers were fabricated at low sintering temperatures. This procedure was followed by ultrasonic pulse-echo measurements, and the data were compared to the modeling results to estimate Young's modulus of the bond between the spray-on transducer and the substrate.

\subsection{Background}

The recent advances in spray-on transducer technology provide a possible avenue toward these objectives. However, conventional spray-on transducers require a hightemperature $\left(>700^{\circ} \mathrm{C}\right)$ sintering process, which can have an effect on the microstructure of the substrate material. For mechanical elbows and valves utilized for fluid transport in the energy sector, the components are designed to have a specific microstructure, and deviations from these specifications can create weak points in the system. For this reason it is important to investigate how the temperature of the deposition process affects the substrate. This paper investigates the effects of both high-temperature and low-temperature $\left(<150{ }^{\circ} \mathrm{C}\right)$ processing conditions on the surface composition of the substrate. Furthermore, the resultant transducers from high- and low-temperature fabrication processes are compared to determine if a low-temperature processing method is feasible. For these studies a sol-gel spray-on process is employed to deposit piezoelectric ceramics onto a stainless-steel 316L substrate.

Results indicate that the high-temperature processing conditions may alter the surface composition of the metal due to a diffusion of the metal into the ceramic, which results in a surface of the metal that is bonded to the ceramic. Furthermore, it is shown that low-temperature processing of spray-on transducers is a viable method for transducer fabrication where the resultant transducers meet the industry minimum requirement of $30 \mathrm{~dB}$ signal-to-noise ratio. Parallel simulation calculations by finite-element fethod (FEM) were performed to model the adhesive strength of the lowtemperature processed transducer to the substrate surface. Comparisons between the simulations and experiments suggest that the bond strength is much greater than the commercial gel bonds and closer to hardened epoxy glue bonds. These results indicate that spray-on transducers fabricated under low-temperature processing conditions are a viable solution for leave-in-place monitoring of structures.

\subsection{Recent developments}

Here a technology is reviewed that shows promise in allowing ultrasonic transducers to be sprayed directly onto a component and left in place for permanent monitoring. Initially developed by Kobayashi, the method for fabricating such transducers utilizes a powder and a solution combined into a slurry and sprayed onto a substrate (Kobayashi et al., 2000; Kobayashi and Yen, 2004). The ceramic is then heated to drive out the binding compounds. A final heat treatment process is applied to the film to densify the microstructure. Then the ceramic is "electroded" (given a metallic electrode on the surface) and electrically poled to create a transducer. There are several advantages to this technique, including, but not limited to, a transducer that does not require a bonding medium, repeatable measurements at a constant position of the transducer, structural health monitoring of complex geometry systems, and high-temperature monitoring capabilities. Selected works of Kobayashi that deal with the concept of the composite spray-on transducer are given in Kobayashi and Yen (2004), Kobayashi et al. (2004, 2006, 2007), and Barrow et al. (1995). The spray-on process was a new deposition technique for thick film deposition of sol-gel ceramics such as the ones characterized by Barrow et al. (1995, 1997). Searfass et al. (2012) investigated high-weigth-percent BiTi and bismuth titanate-lithium niobate composite transducers (Searfass et al. 2010a, b, 2016; Sinding, 2014). Sinding further pursued the concept of composite spray-on transducers. He utilized a micromechanics analysis code by the generalized method of cells to predict for various weight percentages of BiTi the $\mathrm{d}_{33}$ of a transducer fabricated through the conventional spray-on process (Sinding, 2014). The $d_{33}$ is the principal performance-determining parameter for piezoelectric materials and indicates the charge per unit force in the polarization direction of the sample.

While this information is very useful for high-temperature components, it is not always practical or acceptable to implement a high-temperature deposition process for stainlesssteel 316L components used in industrial applications. Piping structures installed in energy production facilities are fabricated to specific standards intended to ensure acceptable microstructures (Kalpakjian and Schmid, 2008; Vander Voort, 1991). The high-temperature sintering process that is conventionally carried out at $850{ }^{\circ} \mathrm{C}$ for the spray-on deposition process may alter the grain structure of the substrate material (Searfass et al., 2010a). Changes in the grain structure can occur at temperatures as low as approximately $550{ }^{\circ} \mathrm{C}$ for stainless steel 316L (American Society for Metals, 1977). When the time-temperature-precipitation diagram is considered, temperatures above $485^{\circ} \mathrm{C}$ may cause a change in the microstructure. The continuous cooling transformation (CCT) diagrams of steels with similar compositions to $316 \mathrm{~L}$ indicate that there could be a transformation as low as $150^{\circ} \mathrm{C}$ upon cooling (Ming and Lu, 2012). 
Another important factor to consider when dealing with an interface between two materials is diffusion bonding between the two different surfaces. Diffusion at a metal and dielectric interface is a well-researched phenomenon. The diffusion of a metal into a dielectric can be modeled by Eq. (1) (Sinding et al., 2014):

$\rho(x, t)=\rho_{s}[1-\operatorname{erf}\{x /(2 \sqrt{\mathrm{D} t})\}]$

where $\rho$ is the concentration of the metal, $\rho_{s}$ is the fixed metal concentration at the metal-dielectric interface, $x$ is the distance from that interface, $t$ is the time in seconds, $D$ is the diffusion coefficient, and erf is the error function. It is important to note that $D$ is an exponential function of temperature. This means that a higher processing temperature at the metal-dielectric interface results in a higher diffusivity at the interface.

\section{Experimental methods}

\subsection{Experimental plan}

The following steps were taken in the experimental studies.

Step 1 Characterization of the spray-on transducer bond.

i. Preparation of fabrication procedure for optical observations.

ii. Preparation of samples for SEM imaging of the interface for higher resolution and contrast.

iii. Preparation of samples for ultrasonic tests by comparing the SNR values for each of the transducers.

Step 2 Modeling and simulation

i. Surveying and then selecting a finite-element method.

ii. Simulating wave propagation in test samples.

iii. Comparing SNR values for different ultrasonic coupling bonds.

Step 3 Transducer performance comparison

i. Introducing the fabrication procedure for the BiTi low-temperature transducer

ii. Showing that the differences in fabrication are acceptable:

i. still having a high weight percent of $\mathrm{BiTi}$;

ii. electrode thickness did not matter.

iii. Establishing the method for making a comparison between a spray-on bond and a commercial adhesive.

\subsection{Spray-on transducer fabrication}

Spray-on transducers were deposited on stainless-steel 316L cylindrical substrates that were $2.54 \mathrm{~cm}$ in diameter and $1.27 \mathrm{~cm}$ in thickness. Three variations of the deposition process were used. The only difference between each process is the temperature employed for each heat treatment. For simplicity and clarity when a heat treatment process is discussed here, it will be referred to with a process label of 1,2 , or 3 . First the substrate was roughened with 200-grit sandpaper. Then the surface was scrubbed with industrial soap and rinsed with water. The surface was then washed with acetone and dried. Next, isopropyl alcohol was used to wash the surface, which was then dried. The protocol for processes 1 and 2 prescribed that the sample was then allowed to sit at $25^{\circ} \mathrm{C}$ for $10 \mathrm{~min}$. Process 3 , however, let the sample sit at $400{ }^{\circ} \mathrm{C}$ for $10 \mathrm{~min}$. After these intermediate processes, the sol-gel solution was mixed. For the mixture, $2.5 \mathrm{~g}$ of lead (II) acetate trihydrate was dissolved into $1.925 \mathrm{~mL}$ of acetic acid. This solution was placed on a hotplate at $100^{\circ} \mathrm{C}$ for $20 \mathrm{~min}$ and then taken off and allowed to cool to room temperature. While this solution was cooling, $1.82 \mathrm{~mL}$ of zirconium propoxide was combined with $1.085 \mathrm{~mL}$ of titanium isoproxide in a separate vial. Next the two solutions were mixed thoroughly until the mixture was completely transparent to form a sol-gel. The sol-gel was either stored for up to approximately 2 months at $70^{\circ} \mathrm{C}$ or was used immediately.

To create the slurry that was sprayed onto the substrate, $2.3 \mathrm{~g}$ bismuth titanate was combined with $1.2 \mathrm{~mL}$ of the solgel. This slurry was mixed with a $25.5 \mathrm{kHz}$ ultrasonic horn to create a homogeneous solution. The solution was then poured into an appropriately sized gravity-feed spray gun that was attached to a pressurized air supply with the regulator set to $20 \mathrm{psi}$. The slurry was sprayed onto the substrate using a simple side-to-side pivot motion while holding the nozzle of the spray gun approximately $30 \mathrm{~cm}$ away from the substrates. The resulting thickness was $\sim 20 \mu \mathrm{m}$ and could consistently cover a $60 \mathrm{~cm}^{2}$ area. After each spray, process 1 samples were heated in a tube furnace at $100^{\circ} \mathrm{C}$ for $3 \mathrm{~h}$, process 2 samples were heated in a tube furnace at $150^{\circ} \mathrm{C}$ for $3 \mathrm{~h}$, and process 3 samples were heated on a hotplate at $400{ }^{\circ} \mathrm{C}$ for $15 \mathrm{~min}$. Each process utilized five spray-on layers. After the final pyrolization step, samples processed with method 3 required one additional heating step, which was carried out with an induction heater to approximately $750^{\circ} \mathrm{C}$ and held for $15 \mathrm{~min}$. Each sample was electroded with $300 \mathrm{~nm}$ of platinum and poled at $55 \mathrm{kV} \mathrm{cm}^{-1}$.

\subsection{Characterization methods for substrate surface effects}

To identify the effects of a high-temperature processing method compared to a low-temperature processing method on a stainless-steel 316L cylinder, processing methods 1 and 3 were compared. In order to identify any surface changes to 
the substrate material, the composition of the stainless-steel 316L sample was taken before the deposition process, utilizing energy-dispersive X-ray spectroscopy (EDS). One substrate had a transducer deposited onto it according to process 1 , and another substrate had a transducer deposited onto it according to process 3 . These samples were neither electroded nor poled. To view the interface between the dielectric sprayon material and the metallic substrate, the sample was sanded on a grinding wheel using 4000-grit sandpaper. The interface was then viewed on a scanning electron microscope (SEM). Once a sufficient image of the interface was collected, the dielectric material was scratched off with a razor, revealing the surface of the substrate. The composition of the surface of the substrate was again determined using EDS. For clarity, process 1 was denoted as the " $100^{\circ} \mathrm{C}$ tube furnace" sample, process 2 was denoted as the " $150^{\circ} \mathrm{C}$ tube furnace" sample, and process 3 was denoted as the "induction-sintered" sample (AK Steel Holding Corp., 2007).

\subsection{Transducer performance}

In order to establish the effectiveness of the low-temperature deposition methods, the resultant transducers were tested. As the deposited piezoelectric was intended to be used as a transducer, the most important parameter to compare was the SNR, which indicated the usability of the transducer; however, material properties also provide insight into the functionality of the transducer. As such, the capacitance, loss tangent, and $\mathrm{d}_{33}$ were measured. The $\mathrm{d}_{33}$ was measured on a Berlincourt $\mathrm{d}_{33}$ meter at $20 \mathrm{~Hz}$. A Stanford LCR meter set to $1.0 \mathrm{~V}$ and $1 \mathrm{kHz}$ was used to measure the loss tangent and the capacitance. The transducers that resulted from the two low-temperature $\left(100\right.$ and $\left.150^{\circ} \mathrm{C}\right)$ deposition processes were compared to a spray-on transducer that resulted from a high-temperature process such as the one outlined by Searfass (Searfass, 2012), where sintering temperatures can be as high as $850^{\circ} \mathrm{C}$ to provide a basis for comparison. The SNR was measured by pulsing the transducer with a Panametrics 5800 pulser-receiver. This device provides a broadband pulse with an energy of $50 \mathrm{uJ}$ and $100 \Omega$ damping. This pulser-receiver was used in the pulse-echo mode (Sinding et al., 2014).

\subsection{Substrate effects}

Figure 1 depicts the interface between the dielectric and the metallic substrate for the $100^{\circ} \mathrm{C}$ tube furnace sample. Although a crack had developed in the ceramic, it was easy to see the interface between the two materials. Figure 1 showed no signs of diffusion at the interface, but diffusion was expected from an atomistic point of view, not a microstructural view. Figure 1 also shows that the interface between the ceramic and the steel was very intimate, suggesting that there was a strong bond between the substrate and the ceramic transducer. Figure 2 depicts the interface between the dielec-

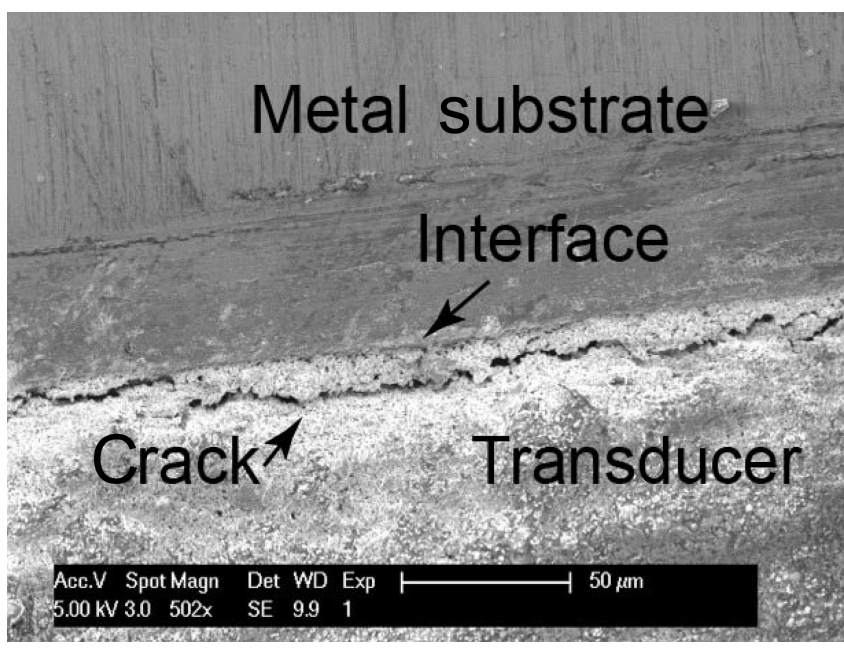

Figure 1. The interface between the ceramic and metal for the $100^{\circ} \mathrm{C}$ tube furnace sample.

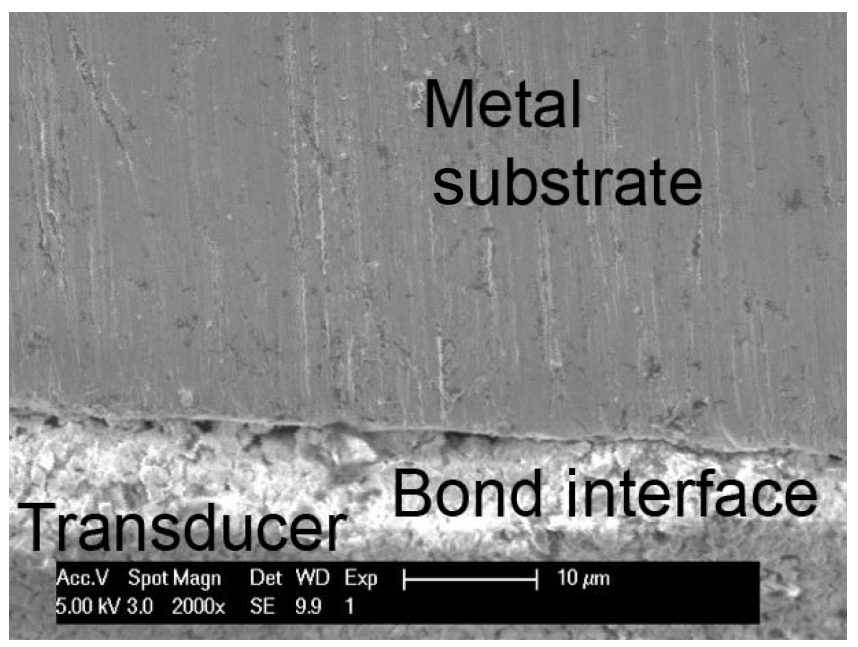

Figure 2. The interface between the ceramic and metal for the induction-sintered sample.

tric transducer and the metallic substrate of the inductionsintered sample. Figure 2 again did not show microscopic diffusion, but this only indicated that the diffusion at the interface was not extremely prevalent and diffusion could have been occurring on a much smaller scale. Noticeable again was that the interface was indicative of a strong bond between the ceramic and the substrate since the two materials seemed to be in contact across most of the interface. If the two materials were not bonded together, the interface would have significantly more pores, such that the two materials would just be touching each other and not bonded together.

Table 1 illustrates the initial weight percent composition of the stainless-steel 316L substrates (Okafor and Nesic, 2007).

A carbide-cutting tool was used to cut the substrates, which seemed to result in extra carbon bonding to the sur- 


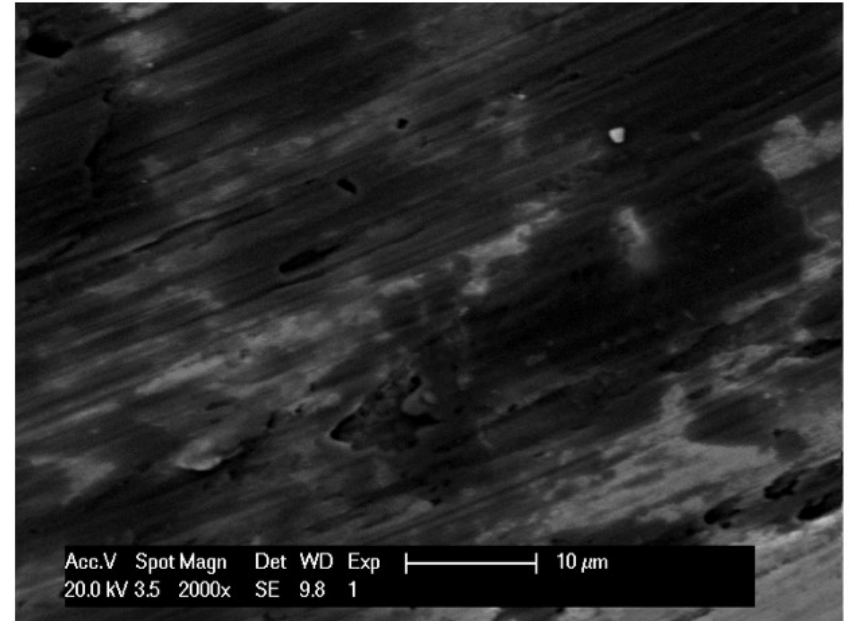

Figure 3. SEM image of the surface of the steel substrate. The lighter regions are less conductive and may indicate that these regions are of higher carbon content due to the use of a carbide-cutting tool to form the surface.

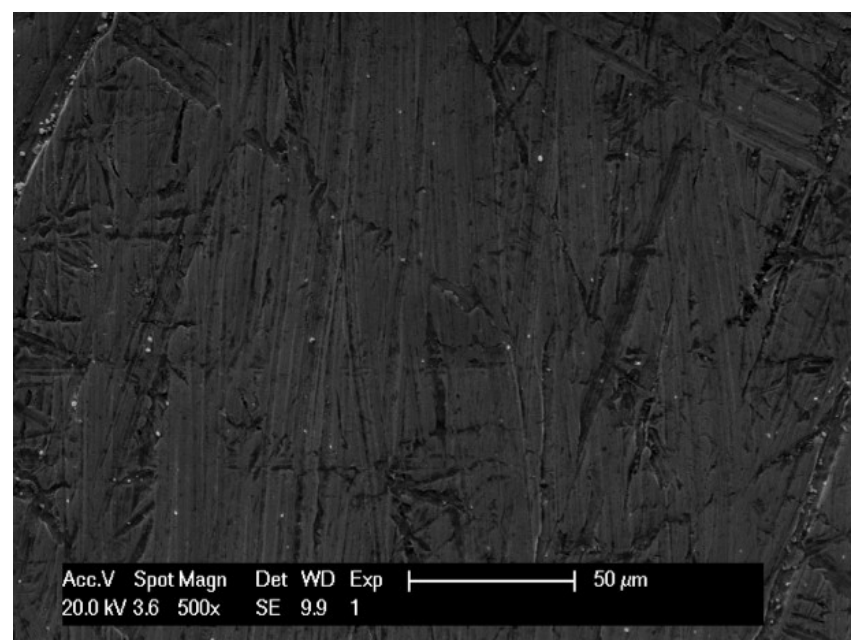

Figure 4. Surface of the steel substrate after the $100^{\circ} \mathrm{C}$ tube furnace deposition process.

face. Figure 3 is an SEM image of the surface of the $316 \mathrm{~L}$ substrate, where the lighter regions indicate that there was some charge buildup - possibly due to higher carbon contents in these regions that lower the electrical conductivity in those regions compared to the rest of the substrate surface. Since the carbon percent was so much higher than its acceptable value, the weight percent of each of the other elements is lower than the actual composition of the $316 \mathrm{~L}$ substrate. If each weight percent is corrected assuming the weight of carbon is actually $0.3 \%$, then all of the elements in the substrate fall within the specified values. The specific EDS machine used for these experiments was supposed to produce only a nominal reading within at best approximately $\pm 0.5 \%$. How-
Table 1. Initial weight percent composition of stainless steel 316L.

\begin{tabular}{lrr}
\hline Element & $\begin{array}{r}\text { Theoretical } \\
\text { weight percent }\end{array}$ & $\begin{array}{r}\text { Experimental } \\
\text { weight percent }\end{array}$ \\
\hline Carbon & $<0.03 \%$ & $12.5 \%$ \\
Chromium & $16-18.5 \%$ & $15.3 \%$ \\
Nickel & $10-14 \%$ & $9.3 \%$ \\
Molybdenum & $2-3 \%$ & $2.4 \%$ \\
\hline
\end{tabular}

Table 2. Experimental weight percent composition of stainless steel $316 \mathrm{~L}$ after transducer fabrication.

\begin{tabular}{lrr}
\hline Element & $\begin{array}{r}100{ }^{\circ} \mathrm{C} \\
\text { tube furnace }\end{array}$ & $\begin{array}{r}\text { Induction- } \\
\text { sintered }\end{array}$ \\
\hline Carbon & $5.33 \%$ & $4.35 \%$ \\
Chromium & $15.63 \%$ & $12.2 \%$ \\
Nickel & $9.81 \%$ & $6.66 \%$ \\
Molybdenum & $2.48 \%$ & $0.0 \%$ \\
Manganese & $1.85 \%$ & $1.42 \%$ \\
Silicon & $0.63 \%$ & $0.0 \%$ \\
Phosphorous & $0.0 \%$ & $0.0 \%$ \\
Sulfur & $0.0 \%$ & $0.0 \%$ \\
Bismuth & $0.0 \%$ & $14.5 \%$ \\
Lead & $0.0 \%$ & $8.65 \%$ \\
Titanium & $0.0 \%$ & $1.83 \%$ \\
Zirconium & $0.0 \%$ & $2.02 \%$ \\
Oxygen & $0.0 \%$ & $3.85 \%$ \\
Iron & $64.2 \%$ & $44.5 \%$ \\
\hline
\end{tabular}

ever, the elements with small weight percent contributions may have had a higher percent error than other elements.

Table 2 presents the results of EDS on the substrates after the respective processing methods.

The weight percent of carbon noticeably dropped between the initial EDS experiment and the final EDS experiment. Although no experiments were performed to investigate this observation, it was noted that acetic acid was the main solvent in the sol-gel, and this acid had been documented to corrode carbon steels (Okafor and Nesic, 2007). This type of reaction could have brought some of the carbon atoms into the sol-gel solution, which was then evaporated out of the ceramic. Furthermore, the longer the acetic acid was allowed to sit on the surface, the longer it was able to dissolve the carbon. For the induction-sintered sample the carbon percent reduced significantly, mainly due to the presence of the bismuth and lead atoms. The actual percent reduction of carbon is small. This is consistent with the previous hypothesis that, since the sample was heated to $400{ }^{\circ} \mathrm{C}$ immediately after the spraying process, there was only a small amount of time for the acetic acid to react with the substrate (Okafor and Nesic, 2007).

Figure 4 is an SEM image of the surface of the steel substrate after the $100^{\circ} \mathrm{C}$ tube furnace deposition process. There are several white specks on the surface of the substrate that 


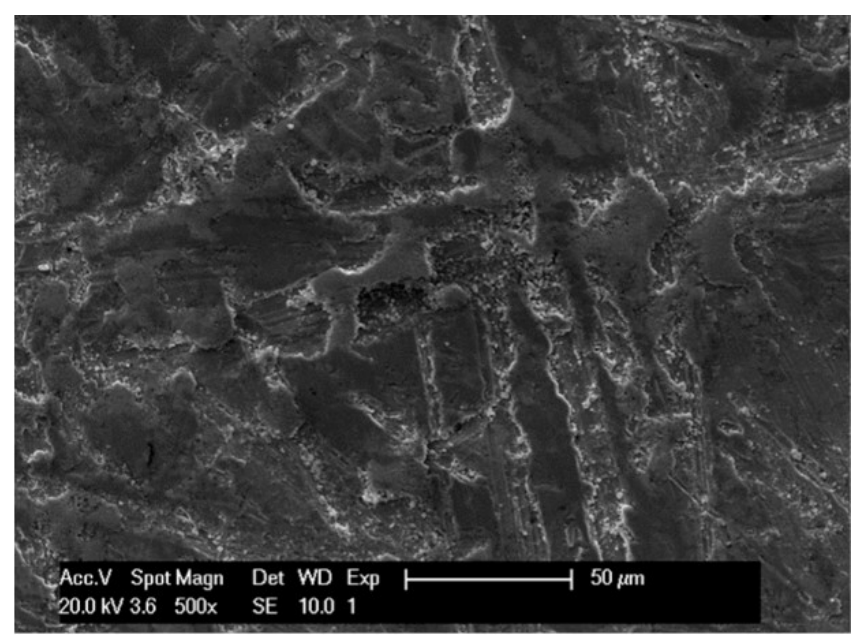

Figure 5. Surface of the steel substrate after the induction-sintering deposition process.

could be small oxides or particles of ceramic that are left after the transducer is scraped off. These small particles produce results that are within the noise level of the EDS spectrum. Figure 5 is an SEM image of the surface of the steel substrate after the induction-sintered deposition process. This image has significantly more bright areas which could be oxide or ceramic, but the relative area of the bright regions to the total image area is still inconsequential. However, the EDS analysis indicated that the surface contains significant weight percentages of bismuth, lead, oxygen, titanium, and zirconium. These are all elements that are present in the transducer. It is hypothesized that the higher temperature during the deposition process allows the diffusion process to begin. The metal slowly diffuses into the ceramic, and the diffusion occurs enough during the high-temperature deposition process to strongly bond a small amount of the transducer material to the substrate, which cannot be removed by a mechanical scraping.

\subsection{Transducer comparison}

Table 3 provides a comparison between the transducers fabricated by the $100^{\circ} \mathrm{C}$ tube furnace and the $150^{\circ} \mathrm{C}$ tube furnace deposition processes and the benchmark high-temperature sintered transducer. It is clear that the conventional transducer generated a signal with a larger SNR, which can be attributed to higher capacitance and $\mathrm{d}_{33}$ values. Industry generally uses a cutoff value of $30 \mathrm{~dB}$ to determine if a transducer is suitable for non-destructive testing. It is important to note each of the deposition processes produced a transducer that meet the industry requirement. This is important because it indicates that the deposition process can be determined successful by adopting the $30 \mathrm{~dB}$ SNR requirement.

As a typical example, the results for a BiTi transducer are shown in Fig. 6. It was fabricated on a $2.54 \mathrm{~cm}$ diame-

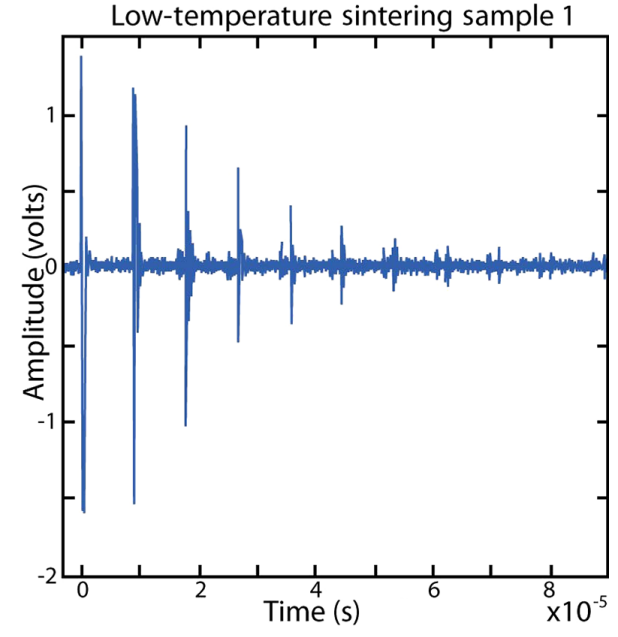

Figure 6. Example of pulse-echo A-scan (relative pulse-echo amplitude vs. time) of low-temperature sintered sample. Notice the large amount of signals produced by the transducer. The receiver gain was at $40 \mathrm{~dB}$. The vertical axis is relative amplitude, which depends on both the transmitter and receiver electronics. The important feature to notice is the high signal-to-noise level.

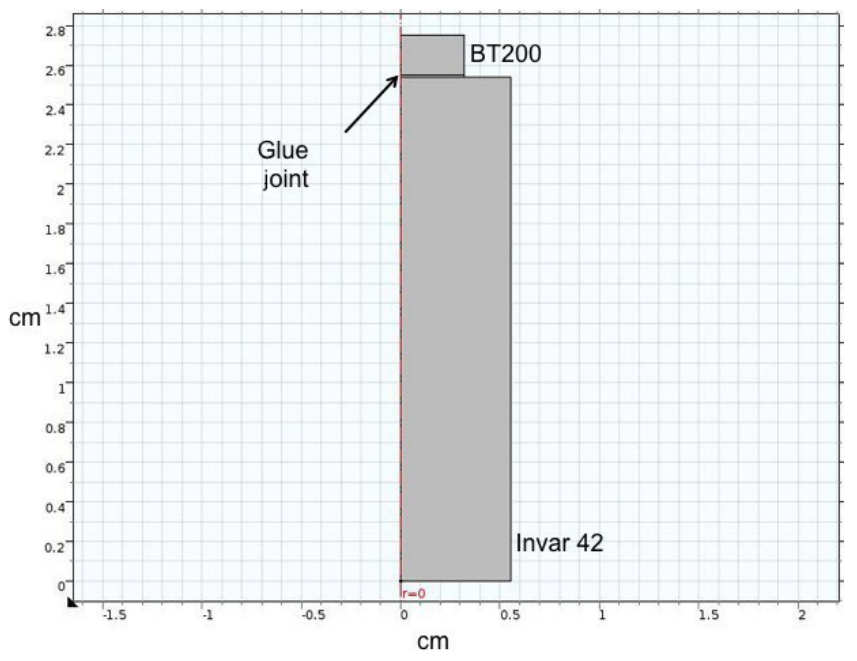

Figure 7. The COMSOL mesh diagram of the system's model.

ter, $2.54 \mathrm{~cm}$ long stainless-steel substrate. The substrate was sprayed five times in a row, giving a thickness of about $100 \mu \mathrm{m}$. The area of the sprayed piezoelectric is nearly the full top area of the cylinder. The sample was then placed in the furnace at $100^{\circ} \mathrm{C}$ for 1 week. After the sample was taken out of the furnace, it was electroded with $100 \mathrm{~nm}$ of platinum and poled. The sample was poled with $380 \mathrm{~V}$ for $20 \mathrm{~min}$ at $98^{\circ} \mathrm{C}$ and cooled with $380 \mathrm{~V}$ applied. The $\mathrm{d}_{33}$ was measured to be $9 \mathrm{pC} / \mathrm{N}$, with a capacitance of $277 \mathrm{pF}$ and a loss tangent of 0.03 . After poling, the sample was tested as a longitudinal transducer in pulse-echo mode. The result is shown in Fig. 6. 
Table 3. Comparison between spray-on transducers fabricated using high- and low-temperature processes.

\begin{tabular}{ccccc}
\hline $\begin{array}{c}\text { Processing } \\
\text { temperature }\end{array}$ & $\begin{array}{c}d_{33} \\
(p \mathrm{C} / \mathrm{N})\end{array}$ & $\begin{array}{c}\text { Capacitance } \\
(\mathrm{pF})\end{array}$ & $\begin{array}{c}\text { Tan delta } \\
(\mathrm{dB})\end{array}$ & $\begin{array}{c}\text { Signal-to-noise ratio } \\
\left({ }^{\circ} \mathrm{C}\right)\end{array}$ \\
\hline 150 & 12 & 669 & 0.035 & 39.9 \\
100 & 10 & 484 & 0.043 & 39.0 \\
750 & 16 & 500 & 0.050 & 34.3 \\
\hline
\end{tabular}

Table 4. Materials used and corresponding Young's modulus values and the resulting peak-to-peak displacement of the wave at the end of the Invar 42 rod from the COMSOL model.

\begin{tabular}{lcc}
\hline Material & Modulus (Pa) & $\begin{array}{c}\text { Displacement amplitude }(\mathrm{cm}) \\
\text { (pk-to-pk at bottom of rod) }\end{array}$ \\
\hline Aremco & $2.01 \mathrm{E}+11$ & $6.009 \mathrm{E}-07$ \\
Silver & $8.30 \mathrm{E}+10$ & $6.025 \mathrm{E}-07$ \\
Glue & $7.65 \mathrm{E}+10$ & $6.076 \mathrm{E}-07$ \\
Epoxy & $3.50 \mathrm{E}+09$ & $4.061 \mathrm{E}-07$ \\
Polypropylene & $9.00 \mathrm{E}+08$ & $1.629 \mathrm{E}-07$ \\
Rubber & $4.00 \mathrm{E}+06$ & $4.061 \mathrm{E}-08$ \\
Commercial gel & $1.89 \mathrm{E}+02$ & $2.507 \mathrm{E}-12$ \\
\hline
\end{tabular}

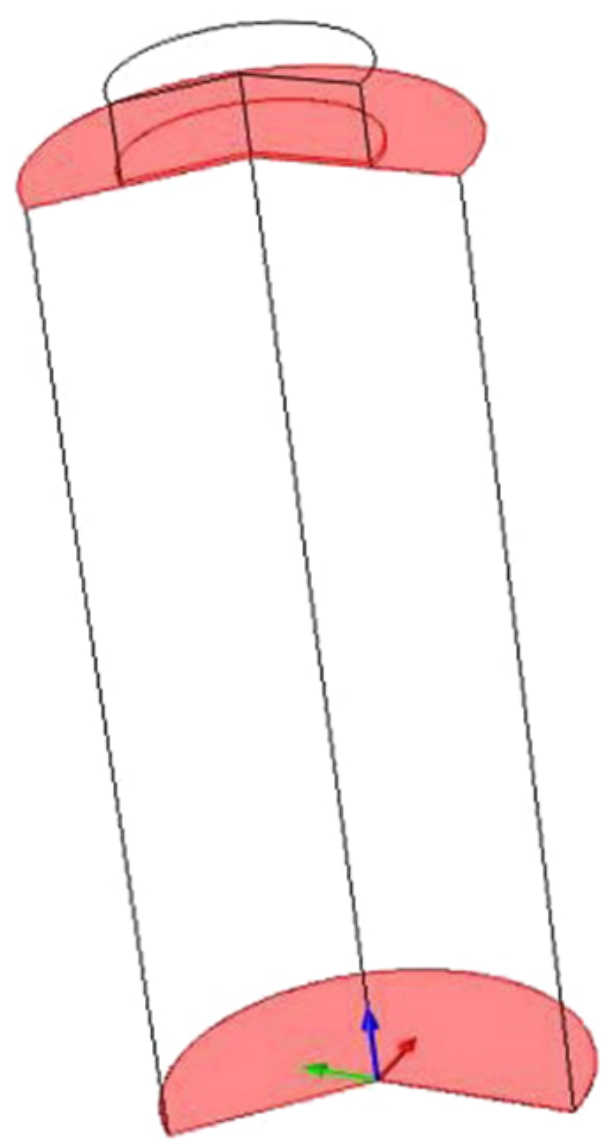

Figure 8. The three planes used to find the average displacement over the area of each vs. time.

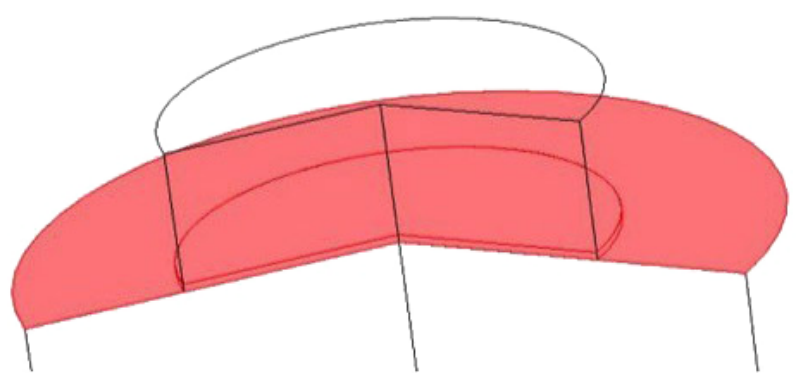

Figure 9. A zoomed-in view of the two planes used at the top of the rod. One plane was at the top of the Invar 42 rod, and the other was at the bottom of the piezoelectric wafer.

\section{The bond strength simulations with finite-element methods}

\subsection{General description}

All of the simulations presented in this work used COMSOL Version 4.4, which is the most recent version as of September 2014. The commands and parameters of the model were inserted into the "Model Builder" tree. For this work, the input frequency was the only parameter needed.

\subsection{Modeling system-bismuth titanate transducer and Invar rod with glue joint}

A model of the system was made to replicate the system used in the experiments (Orr, 2014). The model was built in two dimensions to simplify the model and decrease the computation time. The BT200 piezoelectric ceramic bismuth titanate was a $2 \mathrm{~mm}$ thick, $6.0 \mathrm{~mm}$ diameter wafer (supplied by TRS Ceramics Corp.) Invar was chosen as the material for the cylindrical rods because the thermal expansion coefficients are comparable to those of ceramics. Invar 42 is a $41 \%$ nickel-iron controlled expansion alloy which has been used in a wide variety of glass-to-metal sealing applications. The Invar 42 rod was modeled as a $2.54 \mathrm{~cm}$ long rod with a radius of approximately $0.635 \mathrm{~cm}$. The acoustic coupling bond was modeled as a thin plate approximately $100 \mu \mathrm{m}$ thick, with the same radius as the BT200. The model is shown in Fig. 7. For each geometry used, the material properties needed to be defined. For the Invar 42, the density given by the company was used, but Young's modulus and the Poisson ratio were 

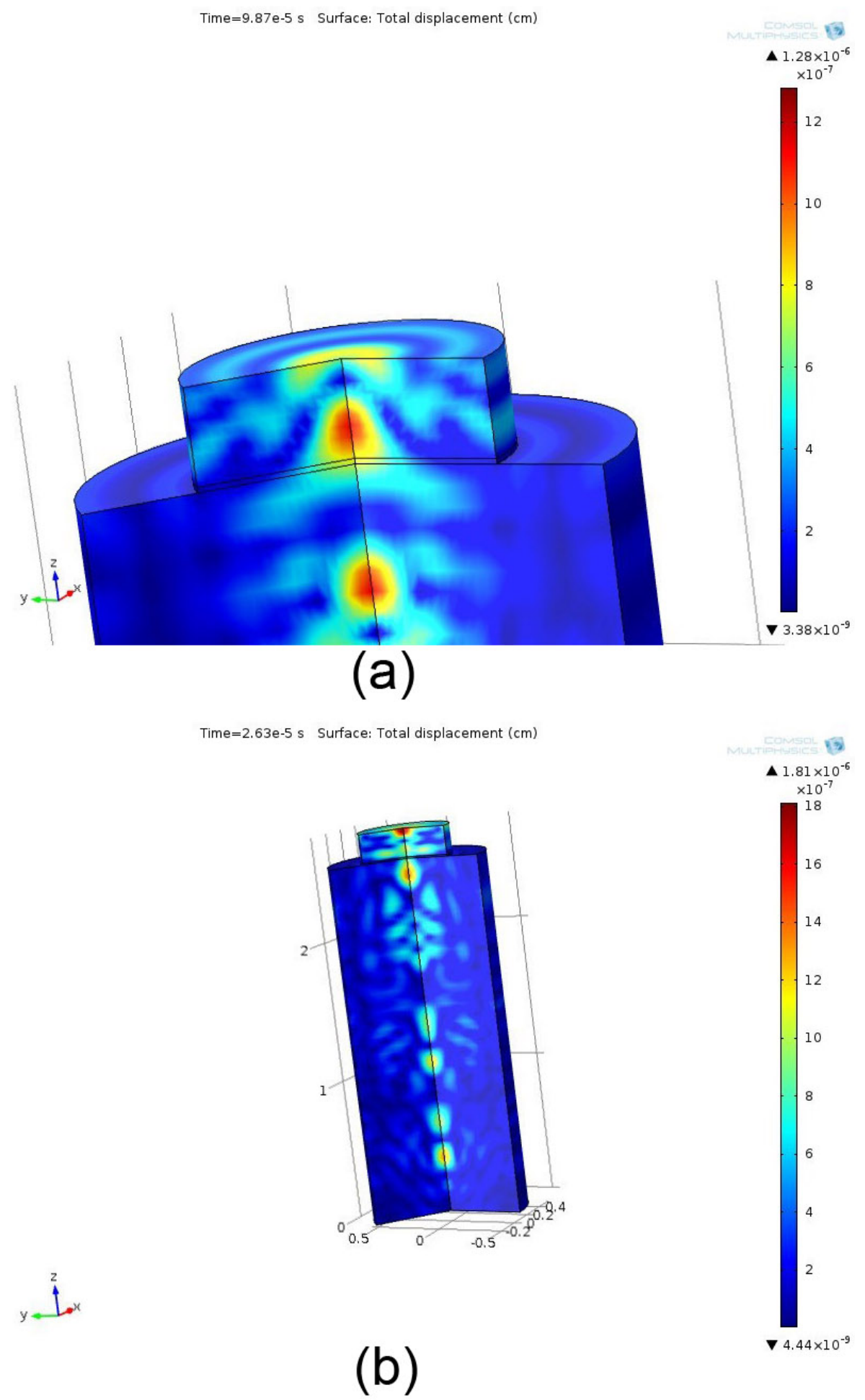

Figure 10. Example of the COMSOL displacement results for the Aremco glue used as the acoustic couplant excited at $1.1 \mathrm{MHz}$ at time $=26.3 \mu \mathrm{s}(4.10 a)$ and time $=98.7 \mu \mathrm{s}$. Notice how most of the energy is able to travel through the coupling layer, and there is dispersion of energy within the rod. Note that all amplitudes are in centimeters. 


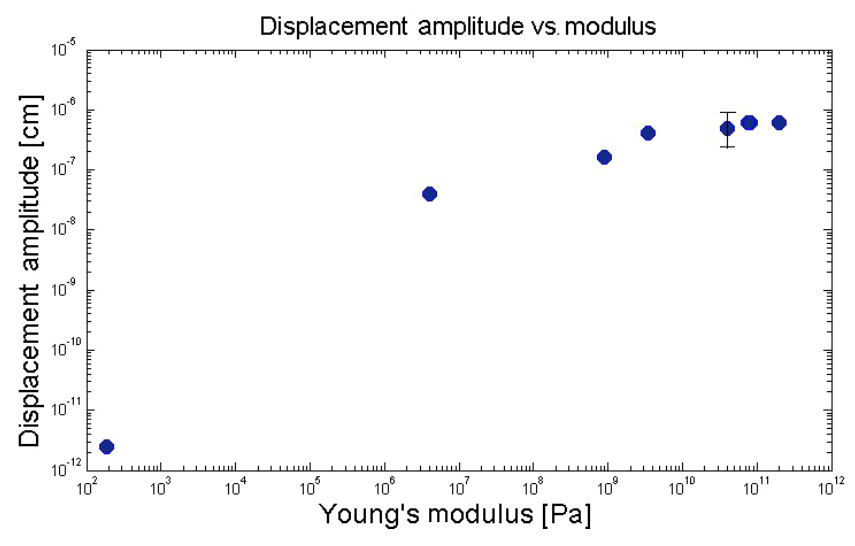

Figure 11. Average peak-to-peak displacement at the bottom of the rod as a function of Young's modulus of the bond materials as simulated with the COMSOL FEM model. The numerical values for various types of bonds are given in Table 4 . The point with the error bars is placed by fitting the displacement amplitude given the estimated modulus of the spray-on low-temperature bond. Bond strength appears to lie between the commercial glue and the epoxy bonds.

estimated based on the literature values for Invar. The bond layer was varied with stiffness, as described below.

In benchtop experiments it was shown that BT200 has similar properties to PZT-5H, so, as a first approximation, PZT$5 \mathrm{H}$ was used for all the material properties used in the simulation.

The boundary condition used on the outer surface was a free boundary condition. The same condition was used on the bottom of the Invar 42 rod. The left side of the entire system has an axial symmetry boundary condition, which is why the radius of each material was used. Again, this was done to expedite the calculation time and to simplify the model. Additionally, since a voltage needed to be applied to the BT200 transducer, the top of the transducer has an electric potential boundary condition, while the bottom of the BT200 wafer was defined as the ground.

The BT200 was modeled using wave propagation in the rod, the transducer, and the very thin coupling joint. The equation used to resolve the mesh was the following:

mesh size $=\frac{c_{0}}{f_{0} u 5}$.

This equation indicated that the maximum size of each element in the mesh is about one-fifth the size of the wavelength associated with the frequency. In this case, $c_{0}$ is the speed of sound in the material. Since three different materials were used in this model, each material had a different mesh size. The $c_{0}$ was the speed of sound associated with the material being meshed. For the thin coupling layer, a finer mesh was needed since the joint was so small. The equation used was the following:

mesh size $=\frac{c_{0}}{f_{0} u 10}$,

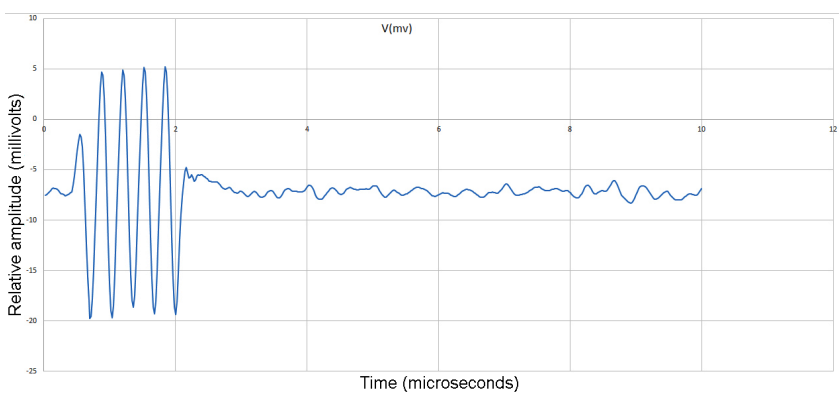

Figure 12. The graph shows the relative amplitude (millivolts) as a function of time (microseconds) as viewed on an oscilloscope with input from a laser interferometer (Polytec Model OFV505) for the out-of-plane displacement of a cylinder surface. The acoustic source is a spray-on bismuth titanate transducer with a $100 \mathrm{~V}$ excitation signal on the opposite end of the cylinder. The cylinder is a metal alloy (Invar 42) with dimensions $1.27 \mathrm{~cm}$ in diameter and $2.54 \mathrm{~cm}$ in length. The estimated signal-to-noise ratio is $28 \mathrm{~dB}$.

\subsection{Simulation results}

A range of stiffness (modulus) values were used for the bond layer to see how it affected wave propagation in the rod and the sensitivity of the transducer. The materials chosen were the approximate values of the Aremco paste, solid silver, commercial glue (Gorilla), epoxy, polypropylene, rubber (polyisobutylene), and commercial ultrasonic gel (Ultragel II from Sonotech Inc.). With each coupling material, the model was solved with a linear solver with the fundamental frequency of $1.1 \mathrm{MHz}$.

For each coupling material, three planes were cut to find the average displacement over the area of the plane, as shown in Figs. 8 and 9. The three planes used were the bottom of the Invar 42 rod, the top of the Invar 42 rod, and the bottom of the piezoelectric wafer. The plane at the bottom of the rod was chosen because it shows how much energy arrives at the bottom of the rod through the coupling layer. The top of the rod was chosen because it shows the propagation of the wave down the rod and also shows the returned wave when reflected from the bottom of the rod. The bottom of the piezoelectric wafer was chosen because it shows the launched wave, as well as what is received by the piezoelectric wafer. The plots of the resulting displacements as a function of time are shown in Fig. 10.

\section{Comparison between COMSOL and experimental results}

The boundary layer between the piezoelectric and the Invar 42 rod were varied to understand the sensitivity of the transducer and the behavior of the wave propagation as the stiffness of the bond changes. Seven different materials were chosen to have a large range of materials and stiffnesses. The average peak-to-peak displacement at the bottom of the rod 
was calculated, and the values are shown in Table 4, whereas a plot of the simulation results are shown in Fig. 11.

The experimental data from the sol-gel fabricated transducers also needed to be compared to the COMSOL model results. Since the stiffness of the boundary layer between the spray-on transducer and the Invar 42 substrate is unknown, it needed to be approximated. Since the bismuth titanate has an oxygen layer on each side of its structure, it was assumed that most of the bonds with the Invar 42 substrate are either nickel oxide or iron oxide.

An average of the two corresponding Young's moduli (Ming and Lu, 2012) were used to approximate the strength of the bond between the composite sol-gel wafer and the Invar 42 rod. Based on this assumption, the sol-gel results fall at about $0.4 \pm 0.1 \times 10^{11} \mathrm{~Pa}$. This places the displacement between epoxy and commercial glue (see Table 4). Measurements of out-of-plane displacement with a laser interferometer (Polytec Model OFV505) gave signals with high signalto-noise ratio $(28 \mathrm{~dB})$ as shown in Fig. 12.

The preliminary conclusion is that the sol-gel spray-on transducers follow the same trend as the theoretical results, showing that, as the stiffness of the bond between the transducer and the substrate increases, the transmitted acoustic energy increases. These results show that, when sprayed onto a substrate, the sol-gel transducer boundary condition appears to be comparable to a commercial glue, which allows for greater transmission of energy than a commercial gel couplant.

\section{Conclusion}

Spray-on transducers were deposited on stainless-steel 316L substrates. The substrates were analyzed to determine the surface effects of a low-temperature and a high-temperature deposition process. It was found that higher-temperature deposition processes promoted a small amount of diffusion from the $316 \mathrm{~L}$ into the sol-gel, which created a strong bond between the ceramic and substrate. The low-temperature deposition process did not develop as strong an adhesion, probably due to a lesser amount of energy applied to the system. Also transducers fabricated through three different deposition processes were compared, and it was found that low-temperature processing of spray-on transducers produced films with reduced properties compared to the highertemperature processing method, but the resulting devices still meet the relevant minimum standards of signal-to-noise ratio.

The finite-element method COMSOL was used to see how the boundary layer between the piezoelectric and an Invar 42 cylindrical substrate was varied to understand the sensitivity of the transducer and the behavior of the wave propagation as the bond stiffness changes. Seven different bonding materials were chosen to have a large range of materials and stiffness. The average peak-to-peak displacement at the bottom of the cylindrical rod was measured and plotted against the Young's modulus value; the values show that as the stiffness (Young's modulus) increases, the average displacement amplitude at the bottom of the rod increases as well. Simulations based on an assumed metal oxide layer between the spray-on transducer and the metal substrate show that the bond strength of the sol-gel transducer appears to be between commercial glue and epoxy.

Edited by: H. Fritze

Reviewed by: two anonymous referees

\section{References}

AK Steel Holding Corp.: 3116/316L Stainless Steel Data Sheet, UNS S31600 and UNS S31603, AK Steel, 9227 Centre Pointe Drive, West Chester, OH 45069, 2007.

American Society for Metals: Atlas of Isothermal Transformation and Cooling Transformation Diagrams, American Society for Metals, Metals Park, Ohio, 1977.

Barrow, D. A., Petroff, T. E., and Sayer, M.: Thick Ceramic Coatings Using a Sol Gel Based Ceramic-Ceramic 0-3 Composite, Surface and Coatings Technology, 76-77, 113-118, 1995.

Barrow, D. A., Petroff, T. E., Tandon, R. P., and Sayer, M.: Characterization of Thick Lead Zirconate Titanate Films Fabricated Using a New Sol Gel Based Process, J. Appl. Phys., 22 81, 876881, 1997.

Chen, W.-K.: Linear Networks and Systems, Belmont, CA, Wadsworth, 123-135, 1993.

Kalpakjian, S. and Schmid, S. R.: Manufacturing Processes for Engineering Materials, Upper Saddle River, NJ, Pearson Education, 2008.

Kobayashi, M. and Jen, C.-K.: Piezoelectric Thick Bismuth Titanate/Lead Zirconate Titanate Composite Film Transducers for Smart NDE of Metals, VTT. Symp., 13, 951-956, 2004.

Kobayashi, M., Olding, T. R., Zou, L., Sayer, M., Jen, C.-K., and Rehmen, A. U.: Piezoelectric Thick Film Ultrasonic Transducers Fabricated by a Spray Technique, in: Proc. IEEE Ultrasonics Symposium, 985-989, 2000.

Kobayashi, M., Jen, C.-K., Ono, Y., and Krüger, S.: Lead-Free Thick Piezoelectric Films as Miniature High Temperature Ultrasonic Transducer, in: Proc. IEEE Ultrasonic Symposium, 13, 910-913, 2004,

Kobayashi, M., Ono, Y., Jen, C.-K., and Cheng, C.-C.: HighTemperature Piezoelectric Film Ultrasonic Transducers by a SolGel Spray Technique and Their Application to Process Monitoring of Polymer Injection Molding, IEEE Sensors, 6, 55-62, 2006.

Kobayashi, M., Jen, C.-K., Nagata, H., Hiruma, Y., Tokutsu, T., and Takenaka, T.: Integrated Ultrasonic Transducers Above $500 \mathrm{C}$, in: Proc. IEEE Ultrasonics Symposium, 10, 953-956, 2007.

Ming, H. and Lu, T.-M.: Metal-dielectric Interfaces in Gigascale Electronics: Thermal and Electrical Stability, Springer, New York, 2012.

Okafor, P. C. and Nesic, S.: Effect of Acetic Acid on Corrosion of Carbon Steel in Vapor-Water Two-Phase Horizontal Flow, Chem. Eng. Commun., 25, 141-157, 2007. 
Orr, A.: A Bond Stiffness Study of Sol-Gel Spray-on Transducers, MS thesis, The Pennsylvania State University, Pennsylvania, 2014.

Searfass, C.: Fabrication and Characterization of Bismuth Titanate Thick Films Fabricated Using a Spray-On Technique for High Temperature Ultrasonic Non-Destructive Evaluation, $\mathrm{PhD}$ thesis, The Pennsylvania State University, Pennsylvania, 2012.

Searfass, C. T., Baba, A., Agrawal, D. K., and Tittmann, B. R.: Fabrication and Testing of Microwave Sintered Sol-gel Sprayon Bismuth Titanate-Lithium Niobate Based Piezoelectric Composites For Use as a High Temperature (> 500 C) Ultrasonics Transducer, Review of Quantitative Nondestructive Evaluation, 1, 1035-1042, 2010a.

Searfass, C. T., Tittmann, B. R., and Agrawal, D. K.: Sol-gel Deposited Thick Film Bismuth Titanate Based Transducer Achieves Operation of 600 C, Rev. Prog. Q., 2, 1751-1758, 2010b.

Searfass, C. T., Pheil, C., Sinding, K., Tittmann, B. R., and Agrawal, D. K.: A Study of Bismuth Titanate (Bi4Ti3O12) Fabricated Using Spray-on Deposition Technique and Microwave Sintering For Use as a High Temperature Ultrasonic Transducer, IEEE T. Ultrason. Ferr., 63, 139-146, doi:10.1109/TUFFC2015.2501241, 2016.
Sinding, K. M.: The Effect Of Weight Percent On The Properties Of Ultrasonic Transducers Fabricated Though A Sol-Gel Deposition Process, dissertation, Pennsylvania State University, University Park, 2014.

Sinding, K., Orr, A., Breon, L., and Tittmann, B. R.: Sol-Gel Spray Technology, Electric Power Research Institute, Charlotte, NC, 2014.

Vander Voort, G. F.: Atlas of Time-Temperature Diagrams for Nonferrous Alloys, ASM International, United States, 474 pp., 1991. 